\title{
Phosphorous-doped bimetallic sulfides embedded in heteroatom-doped carbon nanoarrays for flexible all- solid-state supercapacitors
}

\author{
Shuo $\mathrm{Li}^{1}$, Minghao Hua ${ }^{1}$, Yuan Yang ${ }^{1}$, Xiaowen Zheng ${ }^{1}$, Wei Huang ${ }^{2}$, Pengchao $\mathrm{Si}^{{ }^{*}}$, Lijie $\mathrm{Ci}^{1}$ and \\ Jun Lou $^{3}$
}

\begin{abstract}
Flexible supercapacitors (SCs) have become a popular research topic due to their extra-long service life, foldability, and wearability. Nevertheless, their low energy density restricts their applications. Here, we synthesized phosphorus-doped bimetallic sulfides embedded in heteroatom-doped $(\mathrm{N}, \mathrm{S}$, and $\mathrm{P})$ carbon shells $(\mathrm{P}-\mathrm{ZCS} / \mathrm{HC})$ using a simple approach to create high-performance flexible electrodes. The three-dimensional architecture made by interlaced nanosheets was preserved, and raised nanoparticles appeared on the rough surface during the annealing operation, increasing the specific surface area and potential exposure to the electrolyte. It is noteworthy that the optimal P-ZCS/HC electrode possessed a remarkable capacity of $1080 \mathrm{C} \mathrm{g}^{-1}$ at $1 \mathrm{~A} \mathrm{~g}^{-1}$ along with superb cycling stability. These extraordinary properties were primarily caused by plentiful redox reactions, enhanced conductivity, and synergic effects of the P-doped metal sulfides and heteroatom-doped carbon shells. Density functional theory simulations confirmed the good function of the P-doped electrodes and their ability to boost conductivity, improve reactive dynamics, and promote $\mathrm{OH}^{-}$adsorption. Notably, the assembled all-solid-state hybrid SC exhibited a maximum energy density of $62.9 \mathrm{~W} \mathrm{~h} \mathrm{~kg}^{-1}$ and a power density of $16 \mathrm{~kW} \mathrm{~kg}^{-1}$, while being able to maintain $92.0 \%$ of its initial capacity after 10,000 cycles. This systematic report provides new insight into the design and synthesis of electrodes with complex components and outstanding structures for the flexible energy field.
\end{abstract}

Keywords: supercapacitors, metal sulfides, phosphorus doping, DFT calculations, nanoarrays

\section{INTRODUCTION}

Over the past several decades, flexible devices, such as folding electronic screens, wearable electronics, and portable power tools, have become increasingly attractive [1]. As a consequence, the demands for light weight, high safety, and good flexibility in energy-storage facilities have become high [2]. Flexible supercapacitors (SCs) not only satisfy the above requirements but also possess other desirable characteristics, such as outstanding power density, quick response, and extra-long service life [3,4]. However, their low energy density limits their widespread application and is currently the most pressing issue to be addressed regarding these components [5,6]. An efficient strategy to enhance their energy density is to fabricate flexible hybrid SCs (HSCs) that incorporate battery-type capacitive electrodes to widen the potential window [7-9]. Another method is to increase the specific capacity, which can be accomplished by designing innovative electrode materials. To date, numerous studies have been undertaken with a focus on designing new electrodes for HSCs $[10,11]$. However, engineering and optimizing lowcost and highly conductive electrodes with controllable constructions for flexible SCs remains a challenge.

Recently, transition metal sulfides (TMSs) have received enormous attention, both academic and industrial, due to their improved electroconductivity and reactivity during electrochemical measurements in comparison with oxides/hydroxides [12-15]. Researchers have confirmed that multi-element TMSs possess better performance than single-element TMSs, which is due to

\footnotetext{
${ }^{1}$ Key Laboratory for Liquid-Solid Structural Evolution and Processing of Materials (Ministry of Education), Research Center for Carbon Nanomaterials, School of Materials Science and Engineering, Shandong University, Jinan 250061, China

${ }^{2}$ Department of Chemistry, Technical University of Denmark, DK-2800 Kongens Lyngby, Denmark

${ }^{3}$ Department of Materials Science and NanoEngineering, Rice University, Houston, TX 77005, USA

* Corresponding author (email: pcsi@sdu.edu.cn)
} 
enhanced synergy originating from more abundant redox processes [16]. However, the unsatisfying reaction dynamics and inadequate active sites of TMSs on the nanoscale still hinder their further development in SCs $[14,17]$. Recently, adjusting the compositions of TMSs has stood out as a feasible method to heighten their electrochemical behavior, such as by doping heteroatoms into their original structures [18]. In particular, doping with phosphorus, which has atomic properties very similar to those of sulfur, into the lattice of TMSs has been found to promote their overall performance [19-21]. This phenomenon can be explained by the fact that the substitution of a few $\mathrm{P}$ atoms for $\mathrm{S}$ atoms during $\mathrm{P}$ doping leads to variations in the initial electronic structure, which can generate more available reactive sites and decrease the strain in the electrochemical process [22]. Despite these intriguing advantages, engineering controllable P-doped mixed-metal sulfides with uniformly distributed compositions is still a great challenge because the doping may cause undesirable disordered interfaces and/or the collapse of the compound architecture [19].

In this respect, metal-organic frameworks (MOFs) possessing high specific surface area (SSA) and porous construction have been extensively researched as profitable sacrificial templates for the subsequent synthesis of electrodes with well-designed architectures and tunable components [23]. Indeed, transforming MOFs into other derivatives is simple and highly efficient [24]. However, many traditional MOF-based electrodes are fabricated as powders, in which case a tedious slurry-coating process is required, during which the binder decreases the rate of charge transport [25]. Fabricating two-dimensional (2D) MOF-based materials directly onto 3D conductive substrates can help to effectively avoid this problem and boost the close connection between the material and substrate at the same time. Many studies have used metallic materials as substrates for growing active materials, such as nickel foam [26], copper foam [27], and titanium foil [28], while their rigidity limits their application to flexible products. Hence, carbon cloth (CC) has emerged as the best choice due to its light weight, 3D architecture, and high flexibility. Therefore, researching MOF-derived multivalent P-doped metal sulfides with fixed nanostructures and controllable compositions that grow on $\mathrm{CC}$ as an electrode material is a promising approach for the development of flexible SCs.

Based on this background, we here undertake systematic research on the synthesis strategy, intrinsic features, and electrochemical behavior of P-doped zinccobalt sulfide (ZCS) embedded in heteroatom-doped carbon (HC) shells, which can be denoted as P-ZCS/HC. The developed electrode consisted of multiple anions and cations and was fabricated via a simple room-temperature reaction followed by a two-step ion-exchange process. The P-ZCS/HC network, which grew directly on CC, inherited the $3 \mathrm{D}$ architecture of the MOF precursor, and the resulting well-ordered leaf-like nanosheets possessed uneven surfaces with newly generated nanoparticles. Through alteration of the phosphating parameters, samples with different $\mathrm{P}$ concentrations were obtained, and their properties were investigated. Density functional theory (DFT) simulations were in good agreement with the experimental measurements, demonstrating the enhanced conductivity and positive effects on the reaction kinetics. Overall, the P-ZCS/HC electrode demonstrated outstanding specific capacity and a long cycle life. Impressively, the fabricated $\mathrm{P}-\mathrm{ZCS} / \mathrm{HC} / /$ reduced graphene oxide (RGO) HSC was found to also possess a remarkable energy density of $62.9 \mathrm{~W} \mathrm{~h} \mathrm{~kg}^{-1}$ at $800 \mathrm{~W} \mathrm{~kg}^{-1}$ along with good flexibility and cycling stability. These properties mean the electrode outperforms most previously published phosphide or sulfide electrodes and devices $[16,29,30]$. This work thus leads to tremendous possibility for synthesizing multivalent, heteroatom-doped metallic sulfides with excellent performance and stable architecture by a universal and low-cost strategy to fulfill the high demands of flexible SCs.

\section{EXPERIMENTAL SECTION}

\section{Synthesis of ZnCo MOF on CC}

The CC was submerged in concentrated nitric acid at $50^{\circ} \mathrm{C}$ for $6 \mathrm{~h}$. Afterward, it was rinsed with deionized water (DW) four times and dried under vacuum at $55^{\circ} \mathrm{C}$ for $9 \mathrm{~h}$. Then, the CC was sputtered with a Co target (99.99\% pure) on both sides using a magnetron sputtering system (SKY Company, TRP-450) for 300 s. Finally, it was cut into $2 \mathrm{~cm} \times 2.5 \mathrm{~cm}$ pieces.

Next, $0.179 \mathrm{~g}$ of $\mathrm{Zn}\left(\mathrm{NO}_{3}\right)_{2} \cdot 6 \mathrm{H}_{2} \mathrm{O}$ and $0.524 \mathrm{~g}$ of $\mathrm{Co}\left(\mathrm{NO}_{3}\right)_{2} \cdot 6 \mathrm{H}_{2} \mathrm{O}$ were dispersed in $40 \mathrm{~mL}$ of DW. In addition, $1.314 \mathrm{~g}$ of 2-methylimidazole (2-MIM) was dispersed in $40 \mathrm{~mL} \mathrm{DW}$, and both solutions were magnetically stirred for $15 \mathrm{~min}$. Subsequently, one piece of the aforementioned CC was immersed in the first solution, and the organic ligand solution was then slowly decanted into it. After sitting for $4 \mathrm{~h}$ at room temperature, the violet CC substrate was removed, rinsed with $\mathrm{DW}$, and dried in a vacuum at $55^{\circ} \mathrm{C}$ for $8 \mathrm{~h}$. Co-MOF grown on $\mathrm{CC}$ was prepared by the same method using $0.699 \mathrm{~g}$ of $\mathrm{Co}\left(\mathrm{NO}_{3}\right)_{2} \cdot 6 \mathrm{H}_{2} \mathrm{O}$ without $\mathrm{Zn}\left(\mathrm{NO}_{3}\right)_{2} \cdot 6 \mathrm{H}_{2} \mathrm{O}$. 
Synthesis of $\mathrm{ZnCoS} /$ heteroatom-doped carbon nanosheets on $\mathrm{CC}$

The CC with $\mathrm{ZnCo-MOF}$ was placed in a porcelain boat, and $0.32 \mathrm{~g}$ of sublimed $\mathrm{S}$ was placed in another porcelain boat. The two boats were put into an annealing furnace, with the $S$ situated in the upstream position. Then, the samples were heated at $450^{\circ} \mathrm{C}$ for $2 \mathrm{~h}$ at a $2^{\circ} \mathrm{C} \mathrm{min}{ }^{-1}$ heating rate in Ar. After being cooled, a sample denoted as $\mathrm{ZCS} / \mathrm{HC}$ was fabricated. $\mathrm{A} \mathrm{CoS}_{2} / \mathrm{HC}$ sample was prepared by annealing the Co-MOF on the CC by the same method.

\section{Synthesis of phosphorus- and ZnCoS/heteroatom-doped carbon nanosheet network on CC}

To prepare the electrode on the CC, another thermal phosphating process was required. First, the $\mathrm{CC}$ with the ZCS/HC network was placed in a porcelain boat, and $0.6 \mathrm{~g}$ of $\mathrm{NaH}_{2} \mathrm{PO}_{2}$ powder was placed in another porcelain boat, which was located at the upstream region in the furnace. Then, the electrode was annealed at $350^{\circ} \mathrm{C}$ for $2 \mathrm{~h}$ at a $2^{\circ} \mathrm{C} \min ^{-1}$ heating rate in argon. After being cooled, the electrode on the CC (denoted as P-ZCS/HC) was fabricated. The average weight of the $\mathrm{P}-\mathrm{ZCS} / \mathrm{HC}$ was determined to be approximately $2.5 \mathrm{mg} \mathrm{cm}^{-2}$. In addition, the $\mathrm{ZCS} / \mathrm{HC}$ sample was thermally processed using different $\mathrm{NaH}_{2} \mathrm{PO}_{2}$ contents as controls $(0.3$ and $0.9 \mathrm{~g})$ with different $\mathrm{P} / \mathrm{S}$ ratios (Table $\mathrm{S} 1$ ). The $\mathrm{P} / \mathrm{S}$ ratios were recorded by an energy-dispersive spectrometer, and the samples were labeled P-ZCS/HC-1 and P-ZCS/HC-3.

\section{Electrochemical evaluations}

A CHI 660E electrochemical workstation was used to test the electrochemical behaviors of the active materials. A $6 \mathrm{~mol} \mathrm{~L}^{-1} \mathrm{KOH}$ solution was used as an electrolyte. For the three-electrode measurements, CC with self-supported samples, platinum plates, and calomel electrodes acted as the working, counter, and reference electrodes. The cycle properties were tested through the LAND system. The specific gravimetric capacities $\left(C_{\mathrm{g}}, \mathrm{C} \mathrm{g}^{-1}\right)$ were confirmed by the equation below:

$C_{\mathrm{g}}=\frac{I \times \Delta t}{m}$,

where $I$ expresses the current, $\Delta t$ is the discharging period, and $m$ is the mass of the materials.

\section{Preparation of the all-solid-state hybrid semiconductor device}

The HSC device was prepared using $\mathrm{P}-\mathrm{ZCS} / \mathrm{HC}$ and RGO as the positive and negative electrodes, respectively. The fabrication technique for RGO was outlined in detail in our previous report [31]. The preparation of the RGO slurry was performed by the same method as used previously, and the slurry was coated on CC. The gel electrolyte was synthesized as follows. First, $1 \mathrm{~g}$ of polyvinyl alcohol (PVA) was dissolved into $8 \mathrm{~mL}$ of $\mathrm{DW}$ and constantly stirred at $90^{\circ} \mathrm{C}$ for $1 \mathrm{~h}$. After the gel cooled down to $60^{\circ} \mathrm{C}, 3 \mathrm{~mL}$ of $6 \mathrm{~mol} \mathrm{~L}^{-1} \mathrm{KOH}$ solution was slowly dropped into the gel. After being cooled down, the gel was smeared on the negative and positive CC as well as on the filter paper (separator). Finally, these components were assembled into the HSC device and heated at $60^{\circ} \mathrm{C}$ for $8 \mathrm{~h}$. In consideration of the charge storage theories regarding the different materials in the HSC, the weights of the load on the electrodes follow the formula below:

$\frac{m_{+}}{m_{-}}=\frac{C_{\mathrm{g} c-}}{C_{\mathrm{g} c+}}$.

Here, + represents the positive electrode, and - is the negative one. The energy $(E)$ and power $(P)$ densities follow the equations below, respectively:

$E=\frac{I \int V \mathrm{~d} t}{3.6 \times m}$,

$P=\frac{E \times 3600}{\Delta t}$

where $V$ is the potential range, and $m$ is the mass sum of the positive and negative samples.

\section{DFT calculations}

DFT simulations were performed by the Vienna $A b$ initio Simulation Package (VASP) [32]. The exchange-correlation potential was calculated using the Perdew-BurkeErnzerhof (PBE) scheme [33] with a cutoff energy of $500 \mathrm{eV}$. The Brillouin zone integrations were performed with $11 \times 11 \times 11$ gamma k-point grids for geometry optimization and $13 \times 13 \times 13$ for electronic structure calculations. All the atoms were fully relaxed until the residual force on each atom was lower than $0.02 \mathrm{eV} \AA^{-1}$, and the energy convergence criterion was set as $10^{-5} \mathrm{eV}$.

The $\mathrm{OH}^{-}$adsorption energy can be calculated as follows:

$E_{\text {ads }}=E_{\text {total }}-E_{\text {slab }}-E_{\mathrm{OH}^{-}}$,

where $E_{\text {total }}$ represents the total energy of the ZCS or Pdoped ZCS slab with $\mathrm{OH}^{-}$adsorbed on the surface, $E_{\text {slab }}$ represents the energy of the supercell, and $E_{\mathrm{OH}^{-}}$represents the energy of a single $\mathrm{OH}^{-}$anion.

\section{RESULTS AND DISCUSSION}

The fabrication method for the $3 \mathrm{D}$ self-supporting $\mathrm{P}$ - 
ZCS/HC construction on CC is schematically presented in Fig. 1. The hierarchical P-doped ZCS was grown on CC by a simple room-temperature reaction followed by a two-step thermal treatment, meaning the electrode could be mass-produced at a low cost. At first, the metal ions reacted with the organic ligands to form the well-aligned $\mathrm{ZnCo}-\mathrm{MOF}$ precursor nanosheets on the CC substrate at room temperature. Then, during the annealing procedure in the presence of $S$, the precursors were converted into bimetallic sulfide nanosheets with distributed nanoparticles enveloped by a heteroatom-doped carbon shell. With subsequent thermal treatment, the sulfides were further transformed into P-ZCS/HC in an Ar atmosphere containing $\mathrm{P}$ through an ion-exchange reaction.

The morphologies of the fabricated ZnCo-MOF, ZCS/ HC, and P-ZCS/HC electrodes are shown in Fig. 2. The 2D leaf-like MOF nanosheets were interlaced with one another, forming a 3D architecture (Fig. 2a) with plentiful voids favorable for the permeation of electrolyte [16,34]. As exhibited in the magnified image shown in Fig. 2b, the precursor possessed a very smooth surface. After the $S$ treatment, the interlinked ZCS/HC (Fig. 2c, d) nanosheets maintained their 3D architectures containing open spaces. At the same time, the surfaces of the nanosheets became rough with many nanometer-sized spherical particles. This surface evolution was mainly caused by the etching of $\mathrm{S}^{2-}$ ions [35], and the metal groups aggregated into nanoparticles during the thermal process, a phenomenon that has also appeared in previous studies [36-39]. The exact composition of the ZCS/HC was measured by energy-dispersive X-ray spectroscopy (EDS) tests, as shown in Fig. S1. The atomic percentages of $\mathrm{Zn}$, $\mathrm{Co}$, and $\mathrm{S}$ were found to be $3.1 \%, 6.4 \%$, and $21.1 \%$, respectively. After the phosphating process, the P-ZCS/HC nanosheets (Fig. 2e-h) still evenly covered the CC surface, and the morphology exhibited almost no change compared with ZCS/HC. In addition, the $\mathrm{CoS}_{2} / \mathrm{HC}$ and $\mathrm{P}$ ZCS/HC-1 and -3 electrodes had identical morphologies to $\mathrm{ZCS} / \mathrm{HC}$, as shown in Fig. S2, indicating that the $\mathrm{P}$ doping at different contents and the introduction of $\mathrm{Zn}$ had no effect on the sample morphologies. Such a construction can effectively enlarge the SSA of an electrode, potentially increasing its electrochemical properties [31].

Fig. 3 shows the transmission electron microscopy

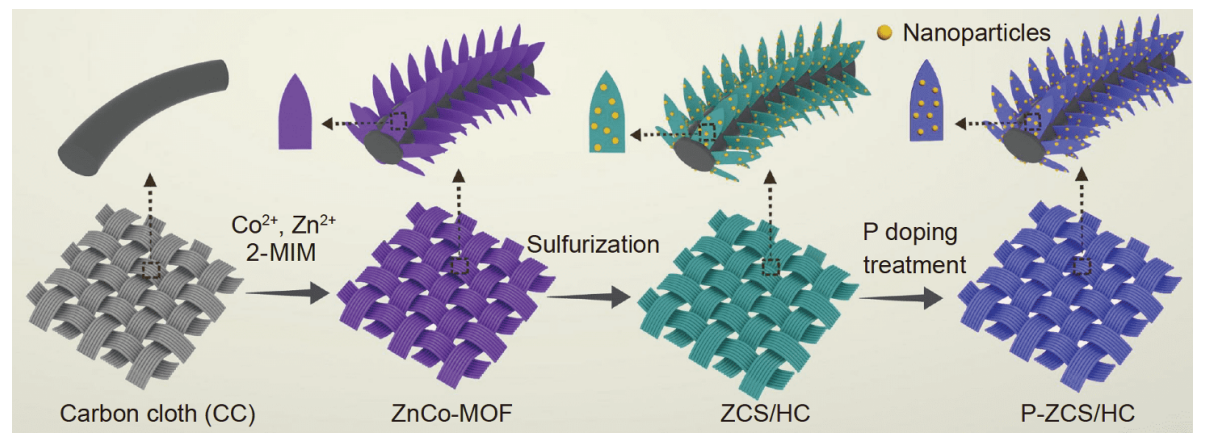

Figure 1 Diagrammatic sketch of the fabrication strategy for P-doped ZCS nanoparticles locked in heteroatom-doped carbon nanoarrays.

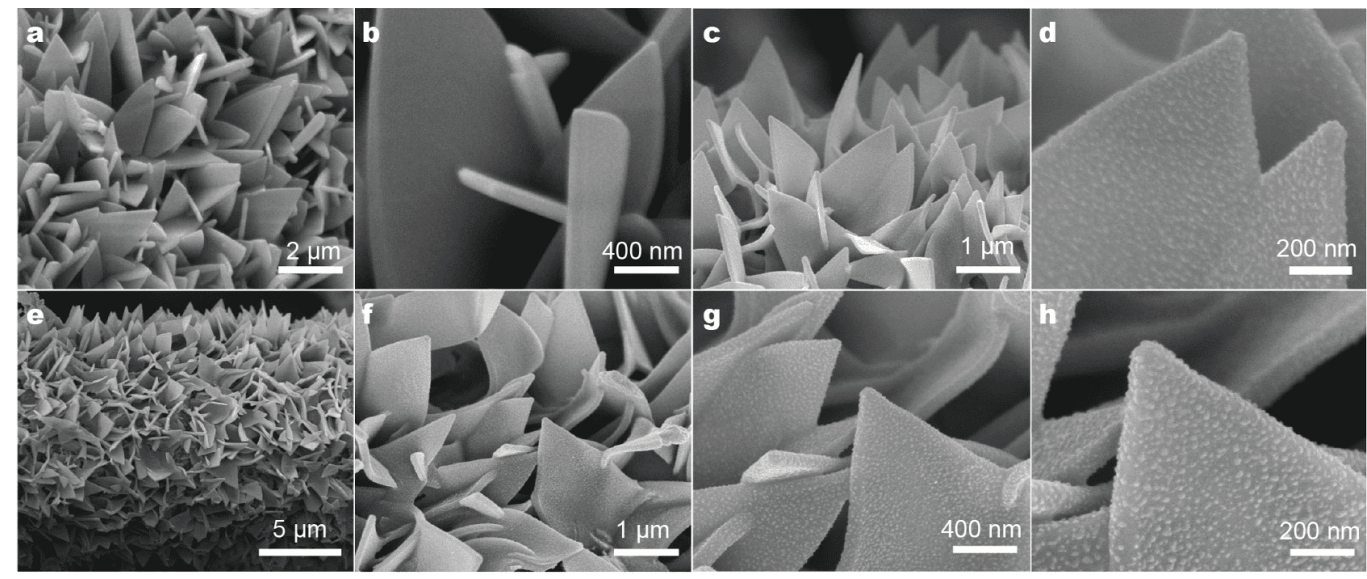

Figure 2 The scanning electron microscopy (SEM) images of (a, b) ZnCo-MOF, (c, d) ZCS/HC nanosheets, and (e-h) P-ZCS/HC nanosheets. 


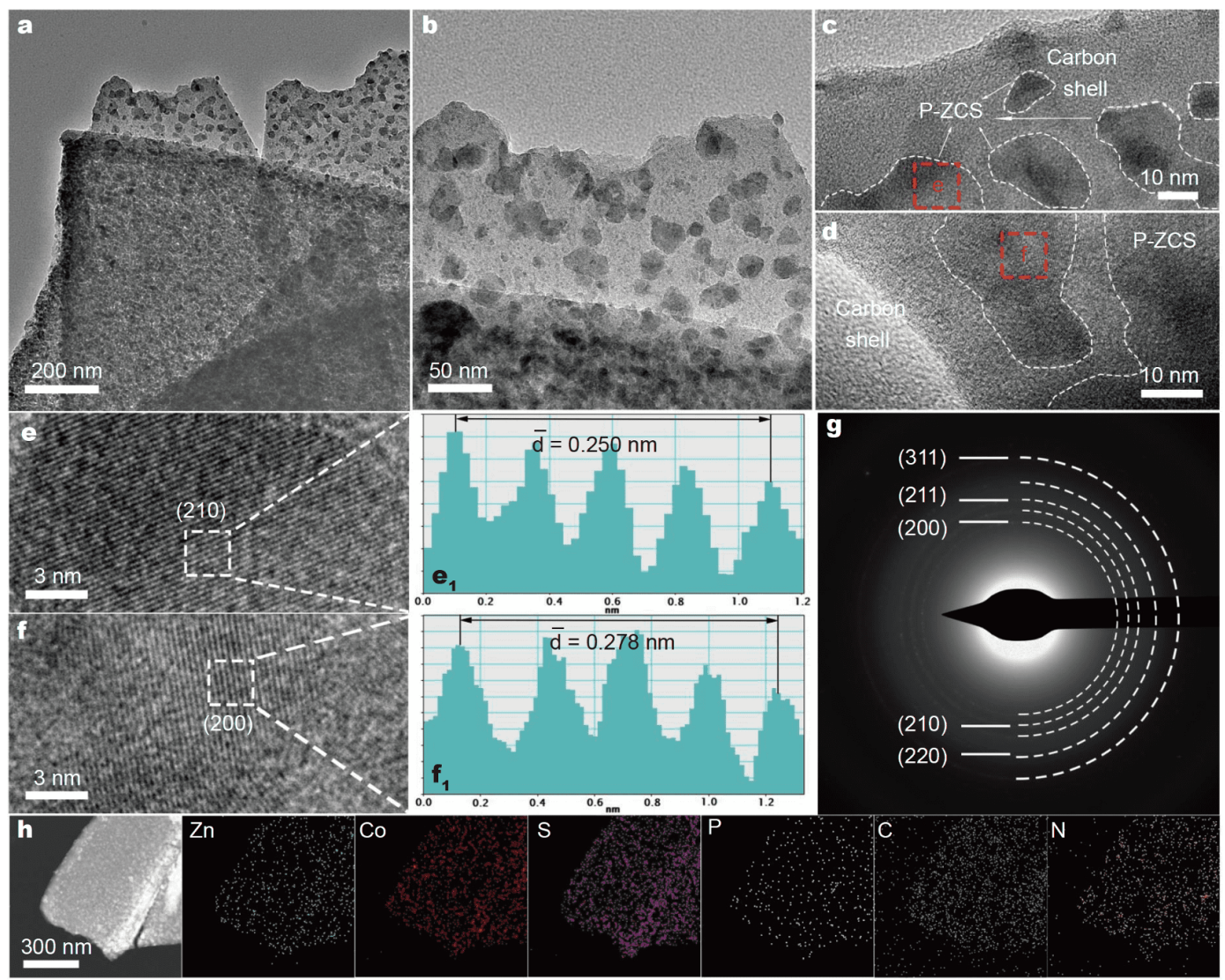

Figure 3 ( $a, b)$ TEM images, ( $c-f$ ) HRTEM images, and (g) SAED pattern of the P-ZCS nanoparticles encapsulated in heteroatom-doped carbon shells, with $\left(e_{1}\right)$ and $\left(f_{1}\right)$ showing the average distances computed from the corresponding diffraction lattice fringes. (h) Elementary EDS mappings of the $\mathrm{P}-\mathrm{ZCS} / \mathrm{HC}$ nanosheet.

(TEM) images of the P-ZCS/HC sample to further reveal the morphological transformation. As shown in Fig. S3a, the precursor nanosheet possessed a perfectly smooth surface. After the sulfurizing process (Fig. S3b, c), the ZCS/HC nanosheets had newly formed uneven surfaces. As the phosphorization proceeded (Fig. 3a, b), the P-ZCS/ $\mathrm{HC}$ nanosheets inherited the surface constructions of the $\mathrm{ZCS} / \mathrm{HC}$, with an abundance of nanoparticles on the nanosheets, indicating good agreement with the SEM morphologies. The high-resolution TEM (HRTEM) images shown in Fig. $3 c$, d verify that the irregular P$\mathrm{ZCS} / \mathrm{HC}$ nanoparticles were tightly encapsulated in the carbon shell. The amplifying HRTEM images (Fig. 3e, f) show that the calculated average fringe spacings were approximately 0.250 and $0.278 \mathrm{~nm}$, corresponding to the (210) and (200) planes of P-ZCS/HC, respectively. These were slightly larger than those of ZCS/HC due to the $\mathrm{P}$ doping (Fig. S3d, e). The well-defined diffraction rings in the selected area electron diffraction (SAED) patterns of P-ZCS/HC (Fig. 3g) and ZCS/HC (Fig. S3f) can be in- dexed to the (200), (210), (211), (220), and (311) planes of $\mathrm{CoS}_{2}$, indicating similar polycrystalline properties. Further, the elemental mappings of the uniformly distributed $\mathrm{Co}, \mathrm{Zn}, \mathrm{S}, \mathrm{P}, \mathrm{C}$, and $\mathrm{N}$ elements in the P-ZCS/HC nanosheet exhibited in Fig. 3h indicate the successful synthesis of the P-doped bimetallic sulfides and the heteroatom-doped carbon shell.

The crystal constructions of the prepared electrodes were characterized using X-ray diffraction (XRD). Fig. S4a shows the XRD results of the $\mathrm{ZnCo}-\mathrm{MOF}$ grown on CC. Aside from the CC peaks, all the other diffraction peaks can be indexed to the zinc-cobalt zeolitic imidazole frameworks without impurities, implying the successful synthesis of ZnCo-MOF [35]. The XRD patterns of the $\mathrm{ZCS} / \mathrm{HC}$ and P-ZCS/HC electrodes shown in Fig. 4a indicate that the ZCSs had identical structures before and after the $\mathrm{P}$ doping and that both were consistent with $\mathrm{CoS}_{2}$ (JCPDS No. 41-1471). There was no newly generated phase of metal phosphide after the phosphating treatment, revealing that the $\mathrm{P}$ atoms occupied only some 

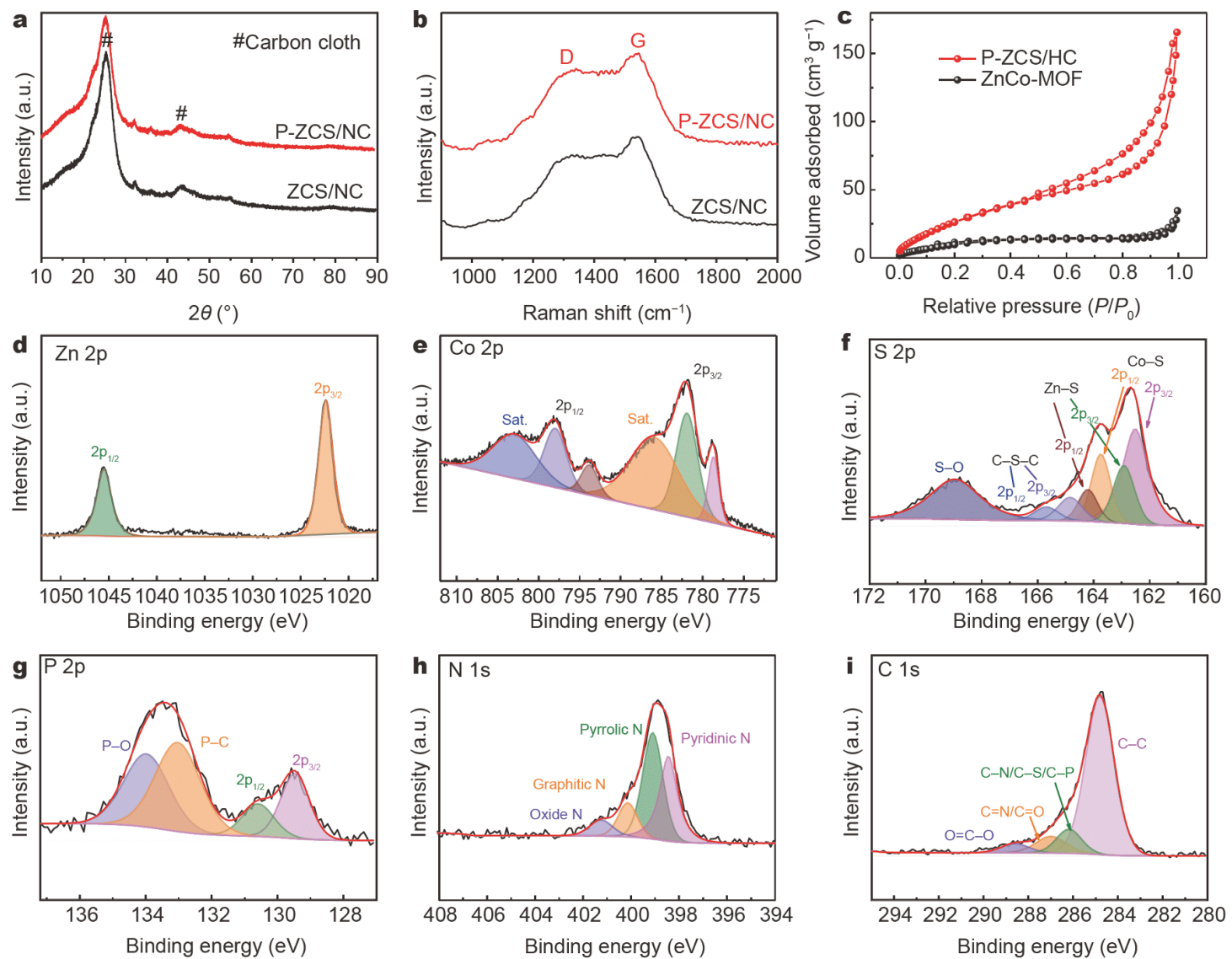

Figure 4 (a) XRD tests and (b) Raman spectra of the P-ZCS/HC and ZCS/HC electrodes. (c) Nitrogen sorption isotherms of the P-ZCS/HC and ZnCo-MOF samples. (d-i) XPS spectra of (d) Zn 2p, (e) Co 2p, (f) S 2p, (g) P 2p, (h) N 1s, and (i) C 1s for the P-ZCS/HC electrode.

of the $\mathrm{S}$ atom sites, and the final product was P-doped sulfide rather than phosphide. In addition, due to the presence of $\mathrm{Zn}$ and $\mathrm{P}$, the diffraction peaks of $\mathrm{P}-\mathrm{ZCS} / \mathrm{HC}$ had a number of deviations compared with those of $\mathrm{CoS}_{2}$ [40]. The XRD patterns of $\mathrm{CoS}_{2} / \mathrm{HC}, \mathrm{P}-\mathrm{ZCS} / \mathrm{HC}-1$, and PZCS/HC-3 shown in Fig. S4b, c reveal the same $\mathrm{CoS}_{2}$ crystal structures. This phenomenon indicates that using different $\mathrm{P}$ contents for doping did not alter the pristine crystalline structure of the sulfide. The XRD analyses fit well with TEM results, again verifying the success of the $P$ doping strategy.

Raman spectroscopy was used to detect the defects and characteristics of these carbonaceous materials. The two peaks around 1341 and $1544 \mathrm{~cm}^{-1}$ shown in Fig. $4 \mathrm{~b}$ corresponded to the $\mathrm{D}$ and $\mathrm{G}$ bands, representing disordered and $\mathrm{sp}^{2}$ hybridized carbon, respectively [38]. Further, the intensity ratio $\left(I_{\mathrm{D}} / I_{\mathrm{G}}\right)$ of P-ZCS/HC (0.89) exceeded that of ZCS/HC (0.85), indicating that additional defects were generated by the doping treatment. This is considered a good result because defects can lead to more approach- able surfaces and charge accumulations, making for easier transmission during the charging and discharging processes [41].

The $\mathrm{N}_{2}$ sorption isotherms of the $\mathrm{ZnCo}-\mathrm{MOF}$ and $\mathrm{P}$ $\mathrm{ZCS} / \mathrm{HC}$ nanosheets were tested to thoroughly investigate their inherent properties. The two type-IV patterns with hysteretic loops shown in Fig. 4c indicate that these electrodes had numerous mesoporous regions [13]. The $\mathrm{P}-\mathrm{ZCS} / \mathrm{HC}$ sample possessed a $77.1-\mathrm{m}^{2} \mathrm{~g}^{-1}$ SSA, which was significantly larger than that of $\mathrm{ZnCo}-\mathrm{MOF}$ $\left(27.8 \mathrm{~m}^{2} \mathrm{~g}^{-1}\right)$. During the annealing processes, the lightweight carbon skeleton transformed into a highly mesoporous structure, which led to the large SSA of the prepared materials. The pore-size distributions of the two materials (Fig. S5) obtained from the Barrett-JoynerHalenda (BJH) analysis reveal that the P-ZCS/HC structure had a greater variety of pores than that of the precursor after the sulfuration and phosphorization treatments. Such a multilevel architecture is conducive not only to the transportation of ions/electrons but also to 
decreasing the internal impedance [37].

The chemical environments of the component elements of the electrodes were researched using X-ray photoelectron spectroscopy (XPS). Fig. 4d-i display the Zn 2p, Co 2p, S 2p, P 2p, N 1s, and C 1s spectra of the P-ZCS/ $\mathrm{HC}$, respectively, and the corresponding spectra of the ZCS/HC sample are displayed in Fig. S6. The two main peaks in the Zn 2p (Fig. 4d) of P-ZCS/HC at 1022.4 and $1045.5 \mathrm{eV}$ corresponded to the $\mathrm{Zn} 2 \mathrm{p}_{3 / 2}$ and $\mathrm{Zn} 2 \mathrm{p}_{1 / 2}$ of $\mathrm{Zn}^{2+}$, respectively [42]. For the Co $2 \mathrm{p}$ region of the $\mathrm{P}-$ $\mathrm{ZCS} / \mathrm{HC}$ shown in Fig. 4e, the peaks at 778.7 and $793.8 \mathrm{eV}$, which belong to Co $2 \mathrm{p}_{3 / 2}$ and $2 \mathrm{p}_{1 / 2}$, respectively, represent the bonding between Co and S or P $[43,44]$. In addition, the peaks at 781.9 and $798.0 \mathrm{eV}$ indicate the existence of oxidative Co arising from surface oxidation [42]. The other two peaks at 785.9 and $803.0 \mathrm{eV}$ were indexed as satellite peaks (marked as "Sat"). Concerning the $\mathrm{Zn} 2 \mathrm{p}$ and Co $2 \mathrm{p}$ regions of the ZCS/HC sample (Fig. S6a, b), the main peaks were located at slightly lower positions in comparison with those of P-ZCS/HC, indicating that the phosphorization process caused the electrode to become more positively charged [44]. Further, the $\mathrm{Co}-\mathrm{S} / \mathrm{Co}-\mathrm{P}$ region grew slightly after the $\mathrm{P}$ doping, which may have been due to the increased combination of Co-P [45]. As for the S $2 \mathrm{p}$ region of $\mathrm{P}-$ ZCS/HC shown in Fig. 4f, the peaks at 162.5 and $163.7 \mathrm{eV}$ were indexed to $S 2 p_{3 / 2}$ and $S 2 p_{1 / 2}$ of Co-S bonds, while the peaks at 162.9 and $164.2 \mathrm{eV}$ fit well with $\mathrm{S} 2 \mathrm{p}_{3 / 2}$ and $\mathrm{S}$ $2 \mathrm{p}_{1 / 2}$ of $\mathrm{Zn}-\mathrm{S}$ bonds [12]. The peaks at 164.8 and $165.6 \mathrm{eV}$ can be ascribed to $\mathrm{C}-\mathrm{S}-\mathrm{C}$ bonds, indicating the combination of $S$ with $C$ atoms $[46,47]$. The peak at $169.0 \mathrm{eV}$ was caused by S-O bonds [48]. For the P $2 p$ spectrum shown in Fig. 4g, the two peaks at 129.5 and $130.6 \mathrm{eV}$ were indexed to $\mathrm{P} 2 \mathrm{p}_{3 / 2}$ and $\mathrm{P} 2 \mathrm{p}_{1 / 2}$, respectively, representing the bonding of $\mathrm{P}$ and metals. The peak at $133.0 \mathrm{eV}$ represents $\mathrm{P}-\mathrm{C}$ bonds, indicating the combination of $\mathrm{P}$ with $\mathrm{C}$ atoms $[49,50]$. The peak at $134.0 \mathrm{eV}$ reflects the existence of phosphate in the superficial position, and this peak has also been present in previously reported P-containing materials [49]. The phosphate peak was relatively strong, indicating phosphate modification on the surface. The $\mathrm{P}-\mathrm{O}$ species on the surface had a positive effect on reducing the free energy barrier and enhancing the electrochemical activity [51-53]. To verify the primary effect of the $\mathrm{P}$ doping on the metal sulfide, it is necessary to investigate the difference in $\mathrm{P}$ species between the surface and bulk materials. We performed depth-profiling XPS on the P-ZCS/HC electrode, a detailed explanation of which is presented in Fig. S7. Accordingly, it was found that phosphate modification existed on the surface, while in the bulk material, the $\mathrm{P}$ species mainly consisted of $\mathrm{P}-\mathrm{C}$ and $\mathrm{M}-\mathrm{P}$ combinations. Compared with the elemental P (130.2 eV), P 2 $\mathrm{p}_{3 / 2}$ moved to a lower-energy position, a phenomenon that also appeared in the $S 2 p$ spectrum, demonstrating that $P$ and $S$ were negatively charged. These elements with opposite charges are able to form strong bonds that may modulate the electronic environments of the P-ZCS/HC network, having a positive effect on the electrochemical behavior $[44,54]$. The N 1s spectrum (Fig. 4h) of the P-ZCS/HC electrode exhibited four $\mathrm{N}$ types: pyridinic $(398.4 \mathrm{eV})$, pyrrolic $(399.1 \mathrm{eV})$, graphitic $(400.1 \mathrm{eV})$, and oxidized $\mathrm{N}$ $(401.2 \mathrm{eV})$ [36]. According to a previous report [55], the relatively high ratios of pyridinic and pyrrolic $\mathrm{N}$ may contribute to better energy storage. The carbon peaks presented in Fig. $4 \mathrm{i}$ can be divided into four sections: $\mathrm{C}-\mathrm{C}$ $(284.8 \mathrm{eV}), \quad \mathrm{C}-\mathrm{N} / \mathrm{C}-\mathrm{S} / \mathrm{C}-\mathrm{P} \quad(286.2 \mathrm{eV}), \quad \mathrm{C}=\mathrm{N} / \mathrm{C}=\mathrm{O}$ $(287.0 \mathrm{eV})$, and $\mathrm{O}=\mathrm{C}-\mathrm{O}(288.6 \mathrm{eV})[56,57]$. These bonds reflect the $\mathrm{N}, \mathrm{S}$, and $\mathrm{P}$ heteroatoms codoped into the carbon network. The XPS measurements indicate that this strategy achieved the successful introduction of $\mathrm{P}$ atoms into the metal sulfide lattices and the codoping of $\mathrm{N}, \mathrm{S}, \mathrm{P}$ heteroatoms in carbon shells.

The different active materials grown on the CC were applied as the electrodes of SCs to study their electrochemical properties. The CC with sputtered Co coating exhibited negligible capacitance in comparison with the other prepared samples (Fig. S8). Fig. S9 shows the electrochemical performance of the electrodes with different $\mathrm{P}$ contents, which was used to investigate the influence of the P doping in detail. The P-ZCS/HC sample possessed a much larger cyclic voltammogram $(\mathrm{CV})$ region and longer discharge period than those of the PZCS/HC-1 and -3 samples, indicating it had better properties. Therefore, the ZCS/HC electrode annealed with $0.6 \mathrm{~g}$ of $\mathrm{NaH}_{2} \mathrm{PO}_{2}$ powder was selected as the optimal electrode.

Fig. 5a displays the CV curves of the P-ZCS/HC material with the voltage ranging from -0.2 to $0.7 \mathrm{~V}$. All the curves were similar, even at $40 \mathrm{mV} \mathrm{s}^{-1}$, illustrating the good rate performance of the material [58]. Each curve presented an evident pair of redox peaks, representing battery-type properties. The movements of anodic and cathodic peaks toward the opposite voltages were primarily due to the interior impedance caused by the rising sweep rates [59]. A comparison of the CV plots among the P-ZCS/HC, ZCS/HC, $\mathrm{CoS}_{2} / \mathrm{HC}$, and $\mathrm{ZnCo}-\mathrm{MOF}$ electrodes is shown in Fig. 5b. Clearly, the P-ZCS/HC exhibited the largest $\mathrm{CV}$ area among them, indicating the presence of additional redox processes after the sulfuriz- 

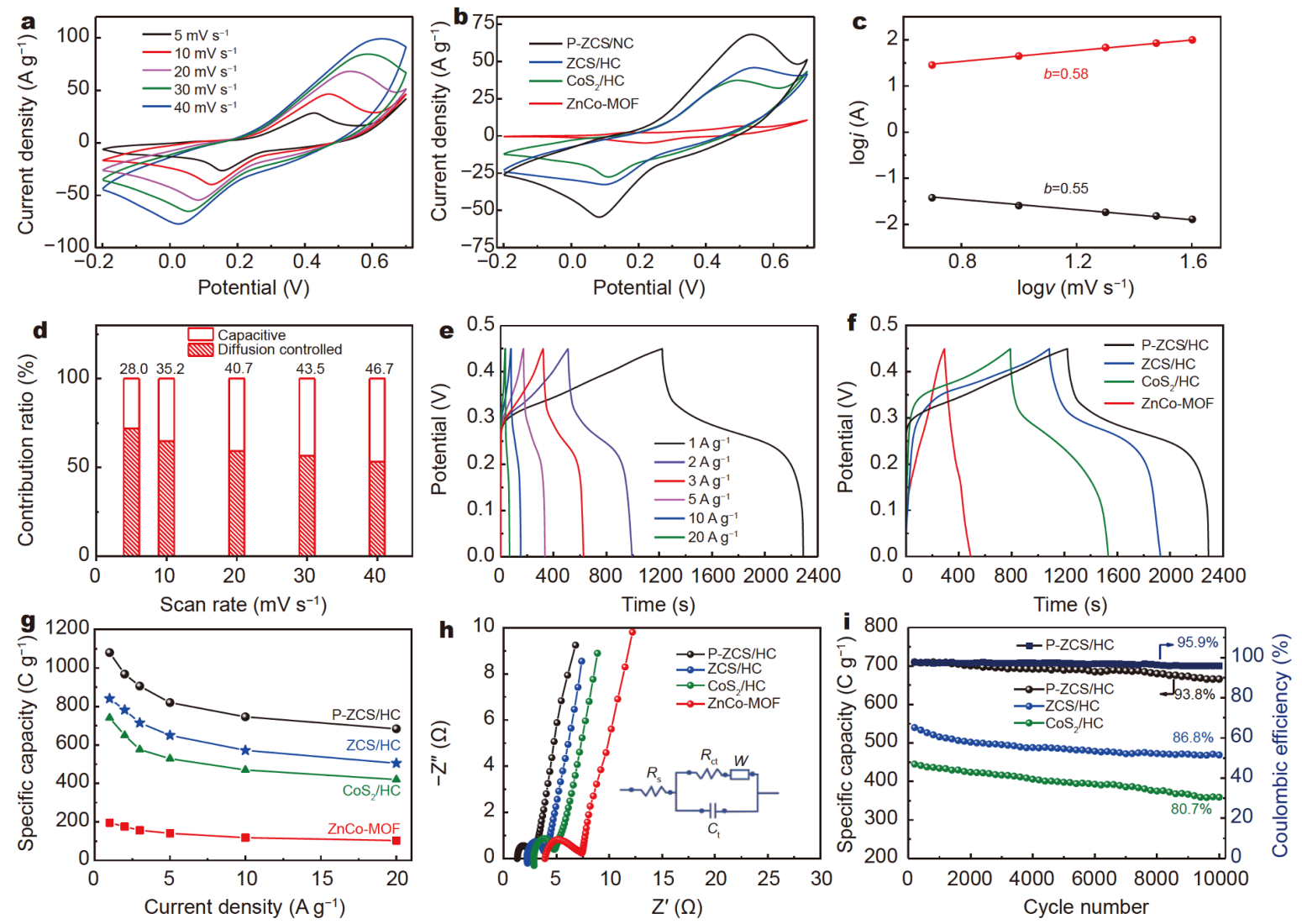

Figure 5 (a) CV plots of the P-ZCS/HC electrode tested at various sweep rates. (b) CV plots of the $\mathrm{ZnCo-MOF}, \mathrm{CoS} / \mathrm{HC}$, ZCS/HC, and P-ZCS/HC electrodes at $20 \mathrm{mV} \mathrm{s}^{-1}$. (c) $b$ values calculated using the peak currents and scan rates of the P-ZCS/HC electrode. (d) Contribution rates of the two different controlled types of the P-ZCS/HC electrode. (e) GCD plots of the P-ZCS/HC electrode measured at 1 to $20 \mathrm{~A} \mathrm{~g}^{-1}$. (f) GCD curves at $1 \mathrm{Ag}^{-1}$, (g) specific capacities under diverse current densities, and (h) EIS and the equivalent electric circuit of the $\mathrm{ZnCo}-\mathrm{MOF}, \mathrm{CoS} / \mathrm{HC}, \mathrm{ZCS} / \mathrm{HC}$, and PZCS/HC electrodes. (i) Cycle performance of the $\mathrm{CoS}_{2} / \mathrm{HC}, \mathrm{ZCS} / \mathrm{HC}$ and P-ZCS/HC electrodes at $15 \mathrm{~A} \mathrm{~g}^{-1}$.

ing treatment and $\mathrm{P}$ doping. The feasible Faradaic reactions originated from the redox reactions of metal ions in the electrodes [60-62]. The redox reactions of this bimetallic sulfide can be expressed as follows [61]:

$$
\begin{aligned}
& \mathrm{CoS}_{2}+\mathrm{OH}^{-} \rightleftarrows \mathrm{CoS}_{2} \mathrm{OH}+\mathrm{e}^{-}, \\
& \mathrm{CoS}_{2} \mathrm{OH}+\mathrm{OH}^{-} \rightleftarrows \mathrm{CoS}_{2} \mathrm{O}+\mathrm{H}_{2} \mathrm{O}+\mathrm{e}^{-}, \\
& \mathrm{ZnS}_{2}+\mathrm{OH}^{-} \rightleftarrows \mathrm{ZnS}_{2} \mathrm{OH}+\mathrm{e}^{-} .
\end{aligned}
$$

Further, this electrode contained N-, S-, and P- codoped carbon materials. Therefore, some of the redox reactions resulted from heteroatom-doped $\mathrm{C}$ and $\mathrm{O}$ containing functional groups. In addition, $\mathrm{CV}$ measurements are good tools to further study energy-storage kinetics. Generally, peak currents (i) have relations with scanning rates $(v)$ [63], as follows:

$i=a v^{b}$,

where $a$ and $b$ are constants. The above formula can be transformed into: $\log i=b \log v+\log a$. The $b$ value reflects whether the redox reaction in the electrochemical process is mainly controlled by the surface $(b=1$ indicates capacitive behavior) or by diffusion ( $b=0.5$ indicates battery-type behavior) [64]. Based on the relations of $\log i$ and $\log v$ presented in Fig. $5 c$, it can be inferred that the PZCS/HC electrode stores charge mainly through a diffusion-controlled redox process. The respective amounts of the capacitance- $\left(k_{1} v\right)$ and diffusion-controlled $\left(k_{2} v^{1 / 2}\right)$ capacities can be quantified as follows:

$i=k_{1} v+k_{2} v^{1 / 2}$,

$i / v^{1 / 2}=k_{1} v^{1 / 2}+k_{2}$,

where $v$ is the sweep rate, and $k_{1}$ and $k_{2}$ can be estimated $v i a$ the relationship between $i / v^{1 / 2}$ and $v^{1 / 2}$. As shown in Fig. 5d, the diffusion-controlled contribution decreased with rising scanning rates, which was caused by the lack of time required for Faradaic reactions at fast scanning 
rates. However, at high sweep rates, the diffusion-controlled process still maintained a dominant position in the $\mathrm{P}-\mathrm{ZCS} / \mathrm{HC}$ electrode, demonstrating its battery-type characteristics and delicate construction advantageous for charge transport [65]. The capacity contributions of the ZCS/HC electrode are shown in Fig. S10, in which it can be seen that the capacitance-controlled capacities were lower than those of the P-ZCS/HC. This phenomenon suggests that the P-ZCS/HC possessed more near-surface active sites to achieve rapid electrochemical responses during the charging and discharging processes, promoting the rate capability $[66,67]$.

Fig. 5e presents the galvanostatic charge/discharge (GCD) measurement results of the P-ZCS/HC electrode at $1-20 \mathrm{~A} \mathrm{~g}^{-1}$ in a range of $0-0.45 \mathrm{~V}$. The nearly symmetric curves indicate good reversible behavior for the charging and discharging processes [59]. Each GCD curve exhibited a voltage plateau, indicating the typical batterytype properties of the P-doped metal sulfide electrode. This phenomenon also fits well with the redox reactions shown in the CV plots. The GCD curves of the P-ZCS/ $\mathrm{HC}, \mathrm{ZCS} / \mathrm{HC}, \mathrm{CoS}_{2} / \mathrm{HC}$, and $\mathrm{ZnCo}-\mathrm{MOF}$ electrodes are shown in Fig. 5f, according to which it is evident that the $\mathrm{P}-\mathrm{ZCS} / \mathrm{HC}$ possessed better energy-storage performance. The specific capacities of the P-ZCS/HC calculated by GCD measurements ranged from $684-1080 \mathrm{C} \mathrm{g}^{-1}$ at current densities of $1-20 \mathrm{~A} \mathrm{~g}^{-1}$, corresponding to area capacities of $2.68-1.69 \mathrm{C} \mathrm{cm}^{-2}$. In comparison with the capacities of the ZCS/HC, $\mathrm{CoS}_{2} / \mathrm{HC}$, and $\mathrm{ZnCo}-\mathrm{MOF}$ electrodes (841, 740, and $196 \mathrm{C} \mathrm{g}^{-1}$, respectively, at $1 \mathrm{~A} \mathrm{~g}^{-1}$ ), the P-ZCS/HC electrode exhibited much higher capacity. The electrochemical measurements of the other three samples are shown in Fig. S11. The coulombic efficiencies of the P-ZCS/HC electrode were less than 100\% but remained at relatively high levels (Fig. S12a). Even at a high current density of $20 \mathrm{~A} \mathrm{~g}^{-1}$, the coulombic efficiency remained at approximately $96.9 \%$. The P-ZCS/HC electrode also exhibited good performance compared with similar materials previously reported (Table S2). The active sites of the electrode materials involved in the redox processes decreased with increasing current densities, and the capacities then decreased, as shown in Fig. $5 \mathrm{~g}$ [13]. Therefore, the sulfurizing and phosphating treatments of the nanosheet electrodes were able to significantly increase their electrochemical properties, especially their specific capacities.

Electric impedance spectroscopy (EIS) is a good method for researching the reaction dynamics of electrodes in detail. Fig. 5h shows the Nyquist plots of the four electrodes with an equivalent circuit, which were recorded from $100 \mathrm{kHz}-0.01 \mathrm{~Hz}$ at a $0.005-\mathrm{V}$ alternating current (AC) perturbation. The plots of each of these four electrodes exhibited an oblique line and a semicircle, indicating behavior typical of SCs. These four electrodes with steep slopes demonstrate that the nanosheets formed constructions with sufficient open spaces to exhibit fast electrolyte diffusion. The diameter of the semicircle expresses the charge transfer resistance $\left(R_{\mathrm{ct}}\right)$, and the $x$ coordinate of the intersection expresses the bulk resistance $\left(R_{\mathrm{s}}\right)$ [68]. Clearly, the P-ZCS/HC electrode exhibited lower resistances $\left(R_{\mathrm{ct}}=1.33 \Omega\right.$ and $\left.R_{\mathrm{s}}=1.30 \Omega\right)$ than those of the ZCS/HC $\left(R_{\mathrm{ct}}=1.68 \Omega\right.$ and $\left.R_{\mathrm{s}}=2.23 \Omega\right)$, $\mathrm{CoS}_{2} / \mathrm{HC}\left(R_{\mathrm{ct}}=1.93 \Omega\right.$ and $\left.R_{\mathrm{s}}=2.87 \Omega\right)$, and ZnCo-MOF $\left(R_{\mathrm{ct}}=3.47 \Omega\right.$ and $\left.R_{\mathrm{s}}=3.92 \Omega\right)$ electrodes. That is, the P$\mathrm{ZCS} / \mathrm{HC}$ electrode possessed a higher ion-transfer rate between the electrode and electrolyte and lower inner resistance than the others. These results indicate that the bimetallic sulfide electrode possessed better reaction kinetics after the $\mathrm{P}$ doping, helping to improve its conductivity and electrochemical properties.

To appraise the working life of the electrodes, we performed successive GCD measurements on the P-ZCS/ $\mathrm{HC}, \mathrm{ZCS} / \mathrm{HC}$, and $\mathrm{CoS}_{2} / \mathrm{HC}$ electrodes at $15 \mathrm{Ag}^{-1}$, as shown in Fig. 5i. Encouragingly, the P-ZCS/HC electrode was able to maintain approximately $93.8 \%$ of its capacity after 10,000 cycles, which was much higher than the retentions of ZCS/HC (86.8\%) and $\mathrm{CoS}_{2} / \mathrm{HC}(80.7 \%)$. In addition, the coulombic efficiencies of the $\mathrm{P}-\mathrm{ZCS} / \mathrm{HC}$, $\mathrm{ZCS} / \mathrm{HC}$, and $\mathrm{CoS}_{2} / \mathrm{HC}$ electrodes after 10,000 cycles at a current density of $15 \mathrm{~A} \mathrm{~g}^{-1}$ were $95.9 \%, 93.1 \%$, and $91.8 \%$, respectively (Fig. 5i and Fig. S12b-d). Therefore, the cyclic stability and reversible behavior of the ZCS/HC electrode were enhanced after the phosphating treatment. The cycling behavior of the P-ZCS/HC was also better than that of other previously synthesized electrodes (Table S2). Further, the morphology, crystal structure, and EIS results of the P-ZCS/HC electrode after 10,000 cycles are shown in Fig. S13. The networks composed of interlinked nanosheets on the $\mathrm{CC}$ were well maintained, while some of the nanosheets had tiny fractures (Fig. S13a-c). There were also many nanoparticles located on the surfaces of the nanosheets, indicating the electrode had unchanged morphology and surface characteristics after 10,000 continuous cycles. The XRD pattern of the P-ZCS/ HC sample after the cycling test (Fig. S13d) revealed the remaining crystal structure of the $\mathrm{CoS}_{2}$. There were only a few diminutions in the peak values, mainly due to the oxidation in the electrochemical processes [13]. The EIS plot shown in Fig. S13e is similar to the curve measured before the test, exhibiting only a small change, reflecting 
the well-maintained capacitive properties and superior charge transfer kinetics after the cycle tests. Overall, our analyses consistently verified the excellent stability of the $\mathrm{P}-\mathrm{ZCS} / \mathrm{HC}$ electrode during the charging and discharging processes.

The remarkable performance of the P-ZCS/HC sample can be principally ascribed to the following factors. First, the two-step thermal approach successfully introduced $S$ and $\mathrm{P}$ atoms into the sample and resulted in increased electrical conductivity, enhancing its electrochemical properties. The $\mathrm{P}-\mathrm{ZCS} / \mathrm{HC}$ electrode contained more redox-reactive sites, and its complex composition improved the reaction dynamics compared with monometallic sulfides or phosphides [66]. Second, the synergy caused by the effective combination of P-doped bimetallic sulfides and heteroatom-doped carbon shells increased the electrochemical performance. In addition, the carbon layer was able to efficiently protect and support the metal materials, resulting in excellent cycling stability. Third, the $3 \mathrm{D}$ construction consisted of $2 \mathrm{D}$ interconnected nanosheets with space among them serving as electrolyte storage rooms and temporary buffers, accelerating the permeation of electrolyte and adapting the volume transformation during the use process [16]. Additionally, the newly generated raised nanoparticles on the surface acted as edge sites to enhance the SSA and exposure to electrolyte [69]. Finally, the self-supporting approach guaranteed tight adhesion between the active materials and CC, establishing a pathway to transmit charges and effectively boosting the cycling stability and reducing the interior impedance caused by the slurry-coating method [12].

To further demonstrate the possible synergic effects and the great enhancement of electrochemical properties originating from the $\mathrm{P}$ doping, we performed calculations on the density of states (DOS). Fig. 6a shows the optimized crystalline structural model of P-ZCS from two viewpoints. This model was derived from the $\mathrm{CoS}_{2}$ structure containing a number of substitutions of $\mathrm{Co}$ and $\mathrm{S}$ with $\mathrm{Zn}$ and $\mathrm{P}$ atoms, respectively, based on the elementary proportions shown in Fig. S14. In addition, the ZCS structure is depicted in Fig. S15. The DOS patterns of ZCS and P-ZCS (Fig. 6b, c, respectively) both exhibited no band gaps at the Fermi level (denoted as $E_{\mathrm{f}}$ ), reflecting the metallic features of the two materials [29]. In addition, the P-ZCS delivered a higher DOS at $E_{\mathrm{f}}$, indicating the higher charge-occupied state and enhanced electron mobility [35]. This result also indicates the more obvious metallic character and the increased conductivity after P doping, which agrees well with the enhanced bonds between the metal ions and anions in the XPS analyses and the decreased bulk resistance in the EIS measurements. The partial DOS (Zn, Co, S, and P) of the P-ZCS shown in Fig. S16 indicates that the outermost $3 \mathrm{~d}$ orbit of Co contributes largely to the electronic state around $E_{\mathrm{f}}$. Due to synergic effects, the primary role of $\mathrm{Zn}$ atoms is to motivate the electroactivity of $\mathrm{Co}$ and accelerate the charge transmission between $\mathrm{Co}$ and $\mathrm{S}$ or $\mathrm{P}$ atoms $[16,23,70]$. The introduction of $\mathrm{Zn}$ in metal compounds can ameliorate the electronic structure, improve con-
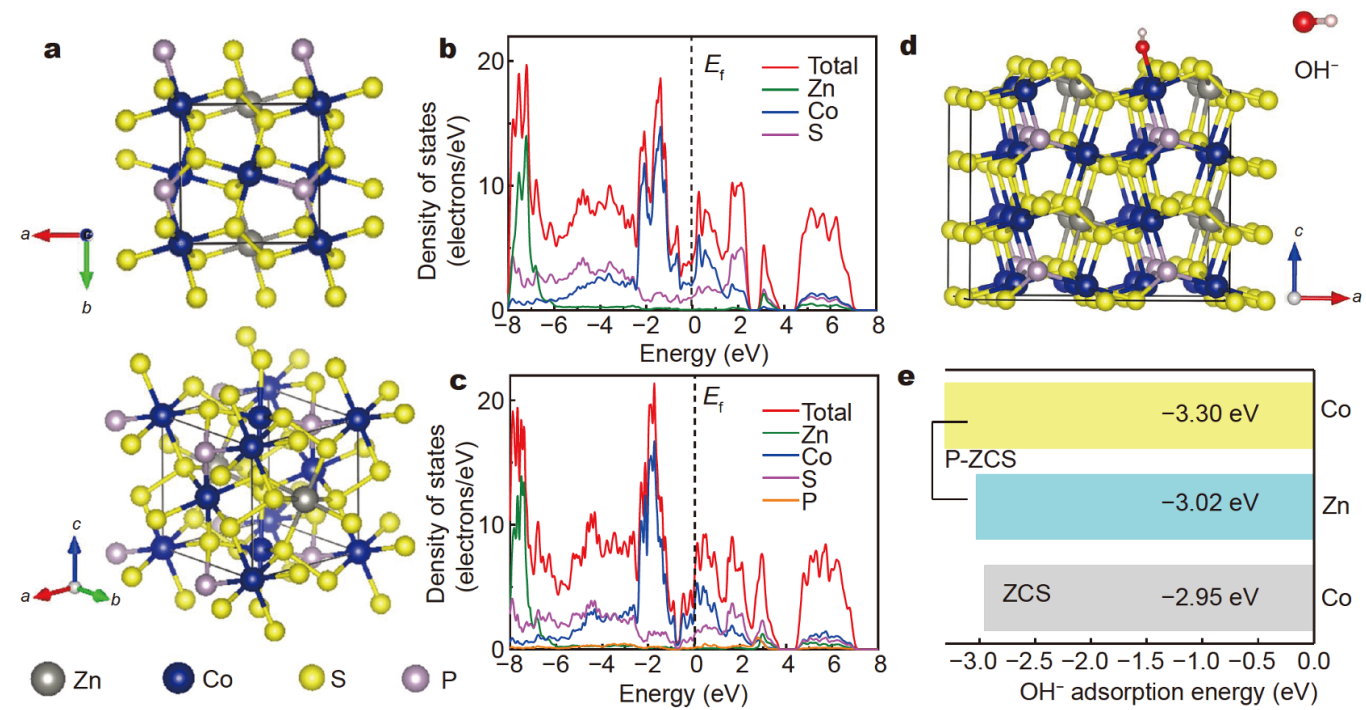

Figure 6 (a) Crystalline structure of P-doped ZCS from two perspectives. DOS of (b) ZCS and (c) P-doped ZCS. (d) Diagrammatic sketch of the $\mathrm{OH}^{-}$adsorption on Co sites of the (200) facet of P-doped ZCS. (e) $\mathrm{OH}^{-}$adsorption energies of different sites in ZCS and P-doped ZCS. 
ductivity, and accelerate electron transport between metal ions and $\mathrm{OH}^{-}$, which is favorable for the $\mathrm{OH}^{-}$adsorption and protonation/deprotonation processes [16]. The partial substitution of $\mathrm{Zn}$ for Co can also decrease the band gap and enhance the charge density at the Fermi level, which can effectively increase the electroactivity and electrochemical performance [70]. Further, $\mathrm{Zn}$ has a strong coordination ability and can easily combine with different metal ions to form stable compounds. The potential synergy from the complex composition of metal compounds can also generate more redox centers [68]. Therefore, bimetallic sulfides possess more plentiful Faradaic reactions in comparison with monometallic sulfides, which can further improve electrochemical performance [68]. Thus, the introduction of $\mathrm{Zn}$ is favorable.

We also carried out simulations on the adsorption energies of $\mathrm{OH}^{-}$on the ZCS and P-ZCS surfaces to further exploit the redox behavior during the electrochemical processes. Based on the XRD and TEM analyses, the (200) facets of ZCS and P-ZCS were selected as the adsorbed surfaces. Fig. S17 and Fig. 6d show the $\mathrm{OH}^{-}$ adsorptions on Co sites of the most stable (200) facets of ZCS and P-ZCS, respectively. The slabs of these two different structures exposed different adsorption sites. In addition to the Co site, the (200) slab of P-ZCS also exposed the $\mathrm{Zn}$ site. As shown in Fig. 6e, the adsorption energy of hydroxyl for P-ZCS was $-3.30 \mathrm{eV}$ (Co site), which is lower than the energy adsorbed on the Co site of ZCS $(-2.95 \mathrm{eV})$. Further, the Zn site of P-ZCS also exhibited a low $\mathrm{OH}^{-}$adsorption energy $(-3.02 \mathrm{eV})$. The low adsorption energies of $\mathrm{OH}^{-}$indicate that P-ZCS has better adsorptive capability and a faster transfer of ions or electrons on the surface between the electrode and electrolyte, facilitating the electrochemical reactions [16]. This simulation result also explains the enhanced contribution of capacitive control to capacity and the decreased charge transfer resistance in the P-ZCS [67]. These results verify that the $\mathrm{P}$ doping in mixed-metal sulfides can improve the electronic structure and conductivity, promoting the synergy between different elements and facilitating $\mathrm{OH}^{-}$adsorption. This ion substitution technique is able to ameliorate the reactive dynamics during the charging and discharging processes and make a great contribution to the electrochemical behavior. It thus has promising potential for application to the design of electrodes in energy-related fields.

All-solid-state flexible HSC devices were also assembled to test the applicability of the electrode in electronic products, following the assembly diagram depicted in Fig. 7a. Fig. S18 shows the electrochemical properties of
RGO. The CV plots $(-1-0 \mathrm{~V})$ were approximately rectangular, and the GCD curves were linear. These tests reflect the typical double-layer electrical behavior of RGO, which clearly differs from that of battery-type electrodes. The stable working voltages of the positive and negative electrodes indicate that the HSC device can be used in a range of $0-1.7 \mathrm{~V}$. The $\mathrm{P}-\mathrm{ZCS} / \mathrm{HC} / / \mathrm{RGO} \mathrm{HSC}$ device was then measured at $20 \mathrm{mV} \mathrm{s}^{-1}$ in operating windows from $0-1.0$ and $0-1.8 \mathrm{~V}$. As can be seen in Fig. $7 \mathrm{~b}$, the $\mathrm{CV}$ areas gradually increased with the rise of working potentials. The oxygen evolution reaction then appeared when the voltage increased beyond $1.6 \mathrm{~V}$. Therefore, the appropriate window was set as $0-1.6 \mathrm{~V}$, and Fig. $7 \mathrm{c}$ shows the $\mathrm{CV}$ tests within this potential range. The shapes of the curves remained consistent at different scanning rates, demonstrating the excellent rate capability. The GCD curves in the corresponding voltage window are depicted in Fig. $7 \mathrm{~d}$, and the nonlinear charging and discharging curves illustrate the Faradaic characteristic of the HSC device. As shown in Fig. 7e, the prepared all-solid-state HSC possessed high specific capacity ranging from $283 \mathrm{C} \mathrm{g}^{-1}$ at $1 \mathrm{~A} \mathrm{~g}^{-1}$ to $160 \mathrm{Cg}^{-1}$ at $20 \mathrm{~A} \mathrm{~g}^{-1}$, exceeding those obtained in many published studies on SCs $[22,23,71]$. The inset in the figure also shows that light-emitting diodes (LEDs) could be successfully lit up by the HSC devices using a serial circuit. The electrochemical behavior of this P-ZCS/HC//RGO HSC device at different bending states was also recorded to further study its flexibility, which is an important indicator of its potential use in flexible devices. As displayed in Fig. 7f, g, this device exhibited nearly overlapping CV patterns and almost identical discharge periods at different bending states, indicating perfect mechanical flexibility. Such an outstanding performance suggests that the two-step thermal treatment method could be used in the future as a universal approach for designing wearable electronic products.

Energy and power densities are also vital factors for estimating the practicability of SCs, and these can be expressed clearly through a Ragone plot. Fig. 7 h provides a comparison of our prepared $\mathrm{P}-\mathrm{ZCS} / \mathrm{HC} / \mathrm{RGO}$ and other reported devices fabricated by similar materials. Notably, the P-ZCS/HC//RGO device exhibited an energy density of $62.9 \mathrm{~W} \mathrm{~h} \mathrm{~kg}^{-1}$ at $800 \mathrm{~W} \mathrm{~kg}^{-1}$ and was able to maintain a density of $35.6 \mathrm{~W} \mathrm{~h} \mathrm{~kg}^{-1}$ at $16 \mathrm{~kW} \mathrm{~kg}^{-1}$. This performance is superior to those of many published devices, such as $\mathrm{P}-\mathrm{NiCo}_{2} \mathrm{~S}_{4} / / \mathrm{AC} \quad\left(42.1 \mathrm{~W} \mathrm{~h} \mathrm{~kg}^{-1}\right.$ at $\left.750 \mathrm{~W} \mathrm{~kg}^{-1}\right) \quad$ [22], $\quad \mathrm{CoS}_{2} / / \mathrm{AC} \quad\left(52.1 \mathrm{~W} \mathrm{~h} \mathrm{~kg}^{-1}\right.$ at $401 \mathrm{~W} \mathrm{~kg}^{-1}$ ) [60], $\mathrm{NiCo}_{2} \mathrm{~S}_{2.2} \mathrm{Se}_{1.8} / / \mathrm{AC}\left(39.6 \mathrm{~W} \mathrm{~h} \mathrm{~kg}^{-1}\right.$ at $\left.1501 \mathrm{~W} \mathrm{~kg}^{-1}\right)$ [71], $\mathrm{Co}_{2} \mathrm{P} / /$ graphene $\left(24 \mathrm{~W} \mathrm{~h} \mathrm{~kg}^{-1}\right.$ at 

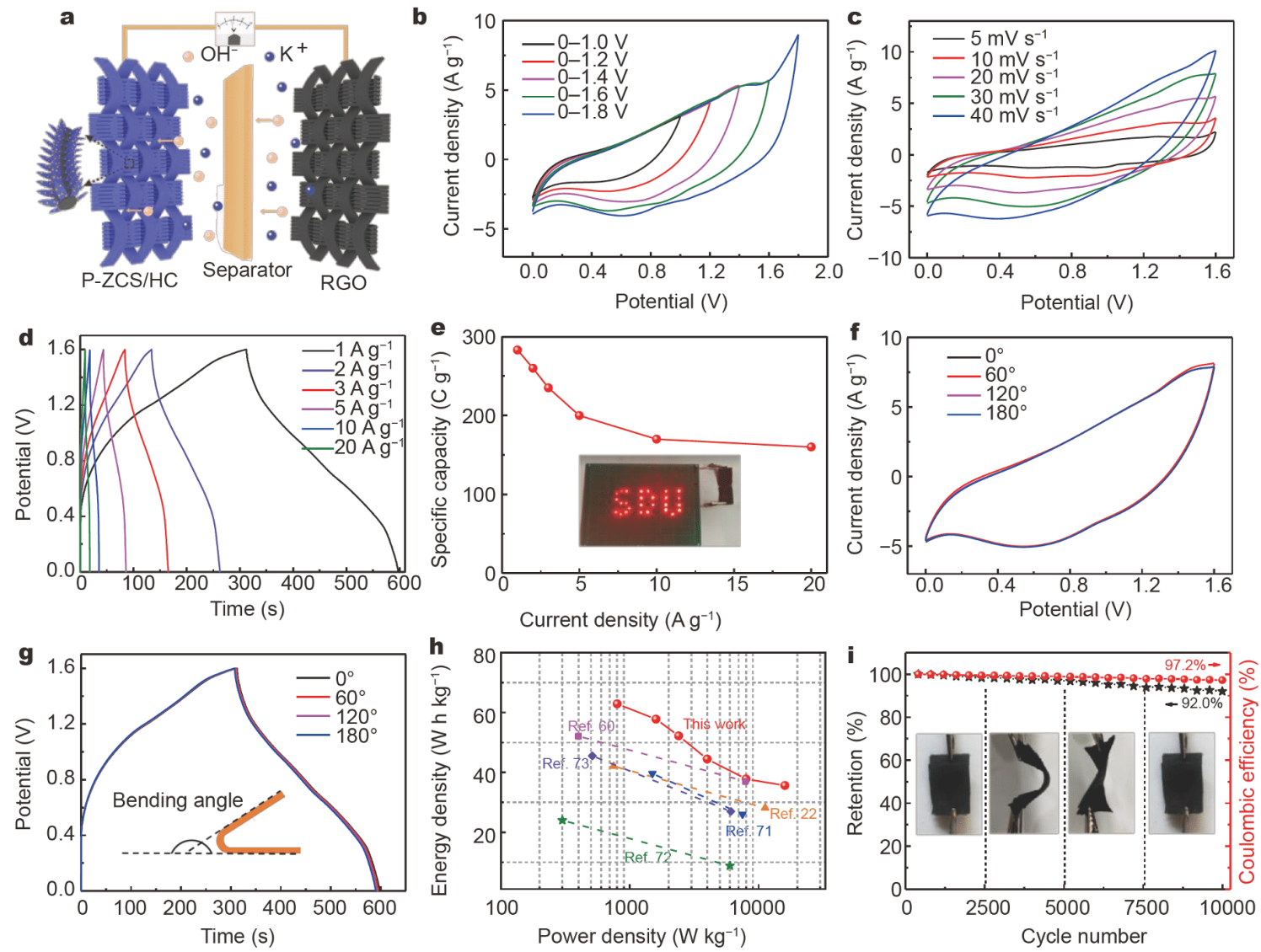

Figure 7 (a) Fabrication sketch of the P-ZCS/HC//RGO HSC. (b) CV plots of this device at diverse voltages and $20 \mathrm{mV} \mathrm{s}^{-1}$. (c) $\mathrm{CV}_{\mathrm{plots}}(0-1.6 \mathrm{~V})$ of this device tested at different sweep rates. (d) GCD plots and (e) specific capacities of P-ZCS/HC//RGO under different current densities, with the inset presenting the successful illumination of the LEDs by two HSC devices in series. (f) CVs at $30 \mathrm{mV} \mathrm{s}^{-1}$ and (g) GCDs at $1 \mathrm{~A} \mathrm{~g}^{-1}$ of this HSC at different bending angles, with the insets displaying the diagrams of the bending angles. (h) The Ragone plot of the P-ZCS/HC//RGO compared with those from analogous works. (i) The cycling performance and coulombic efficiency of the HSC at a flat, bent, and twisted status at $5 \mathrm{Ag}^{-1}$ over 10,000 cycles.

$300 \mathrm{~W} \mathrm{~kg}^{-1}$ ) [72], and $\mathrm{NiCo}_{2} \mathrm{~S}_{4} / /$ ordered mesoporous carbon (45.5 W h kg at $512 \mathrm{~W} \mathrm{~kg}^{-1}$ ) [73], among others (Table S3). The results of a cycling test of the HSC at flat, bent, and twisted status are exhibited in Fig. 7i. After $10,000 \mathrm{GCD}$ measurements at $5 \mathrm{~A} \mathrm{~g}^{-1}$, approximately $92.0 \%$ of the capacity and $97.2 \%$ of the coulombic efficiency were maintained, even when the device was bent and twisted. In addition, the last five GCD curves shown in Fig. S19 remained perfectly symmetrical, reflecting superior cycling stability, mechanical flexibility, and reversibility.

\section{CONCLUSIONS}

In this study, we propose a two-step thermal treatment approach that completely converts the precursors ( $\mathrm{ZnCo}$ $\mathrm{MOF}$ ) into ZCSs via $\mathrm{P}$ doping (P-ZCS/HC) to fabricate flexible electrodes with complex components and porous structures. A 3D architecture with interlaced nanosheets was integrally preserved, and raised nanoparticles appeared on the rough surface during the annealing operations, increasing the SSA and exposure to electrolyte. The optimal P-ZCS/HC electrode possessed a remarkable capacity of $1080 \mathrm{C} \mathrm{g}^{-1}$ at $1 \mathrm{~A} \mathrm{~g}^{-1}$ along with superb cycling stability. These extraordinary properties were mainly caused by the plentiful redox reactions, enhanced conductivity, and synergic effects between the P-doped metal sulfides and heteroatom-doped carbon shells. DFT simulations attested to the boosted conductivity, improvd reactive dynamics and promoted $\mathrm{OH}^{-}$adsorption of these P-doped bimetallic sulfides. Further, the prepared HSC device exhibited energy and power densities up to $62.9 \mathrm{~W} \mathrm{~h} \mathrm{~kg}^{-1}$ and $16 \mathrm{~kW} \mathrm{~kg}^{-1}$, respectively, with a retention of $92.0 \%$ over 10,000 cycles. The report further explored the advantages of P-doped mixed-metal sulfides 
by experiments and theoretical simulations, indicating its promising status as a candidate for novel flexible electrodes. Overall, this research presents an applicable methodology for engineering advanced materials with sophisticated compositions and superior electrochemical performance via an ion substitution approach, which can be widely used in the energy field.

\section{Received 27 December 2020; accepted 17 March 2021;} published online 9 June 2021

1 Liu W, Song MS, Kong B, et al. Flexible and stretchable energy storage: Recent advances and future perspectives. Adv Mater, 2017, 29: 1603436

2 Lv T, Liu M, Zhu D, et al. Nanocarbon-based materials for flexible all-solid-state supercapacitors. Adv Mater, 2018, 30: 1705489

3 Yao B, Zhang J, Kou T, et al. Paper-based electrodes for flexible energy storage devices. Adv Sci, 2017, 4: 1700107

4 Kumar KS, Choudhary N, Jung Y, et al. Recent advances in twodimensional nanomaterials for supercapacitor electrode applications. ACS Energy Lett, 2018, 3: 482-495

5 Qu G, Cheng J, Li X, et al. A fiber supercapacitor with high energy density based on hollow graphene/conducting polymer fiber electrode. Adv Mater, 2016, 28: 3646-3652

$6 \mathrm{Yu} \mathrm{J,} \mathrm{Lu} \mathrm{W,} \mathrm{Smith} \mathrm{JP,} \mathrm{et} \mathrm{al.} \mathrm{A} \mathrm{high} \mathrm{performance} \mathrm{stretchable}$ asymmetric fiber-shaped supercapacitor with a core-sheath helical structure. Adv Energy Mater, 2017, 7: 1600976

7 Zhao Y, He X, Chen R, et al. A flexible all-solid-state asymmetric supercapacitors based on hierarchical carbon cloth@CoMoO $\mathrm{C}_{4}$ NiCo layered double hydroxide core-shell heterostructures. Chem Eng J, 2018, 352: 29-38

8 He X, Zhao Y, Chen R, et al. Hierarchical $\mathrm{FeCo}_{2} \mathrm{O}_{4} @$ polypyrrole core/shell nanowires on carbon cloth for high-performance flexible all-solid-state asymmetric supercapacitors. ACS Sustain Chem Eng, 2018, 6: 14945-14954

9 Xu W, Jiang Z, Yang Q, et al. Approaching the lithium-manganese oxides' energy storage limit with $\mathrm{Li}_{2} \mathrm{MnO}_{3}$ nanorods for highperformance supercapacitor. Nano Energy, 2018, 43: 168-176

10 Chen $\mathrm{L}$, Chen L, Zhai W, et al. Tunable synthesis of $\mathrm{Li}_{x} \mathrm{MnO}_{2}$ nanowires for aqueous Li-ion hybrid supercapacitor with high rate capability and ultra-long cycle life. J Power Sources, 2019, 413: 302-309

11 Zhang $\mathrm{Y}$, Chen $\mathrm{L}$, Hao C, et al. Potassium pre-inserted $\mathrm{K}_{1.04} \mathrm{Mn}_{8} \mathrm{O}_{16}$ as cathode materials for aqueous $\mathrm{Li}$-ion and $\mathrm{Na}$-ion hybrid capacitors. J Energy Chem, 2020, 46: 53-61

12 Yang Y, Huang W, Li S, et al. Surfactant-dependent flower- and grass-like $\mathrm{Zn}_{0.76} \mathrm{Co}_{0.24} \mathrm{~S}_{/} \mathrm{Co}_{3} \mathrm{~S}_{4}$ for high-performance all-solid-state asymmetric supercapacitors. J Mater Chem A, 2018, 6: 2283022839

13 Li S, Huang W, Yang Y, et al. Hierarchical layer-by-layer porous $\mathrm{FeCo}_{2} \mathrm{~S}_{4} @ \mathrm{Ni}(\mathrm{OH})_{2}$ arrays for all-solid-state asymmetric supercapacitors. J Mater Chem A, 2018, 6: 20480-20490

14 Yang J, Yu C, Fan X, et al. Electroactive edge site-enriched nickelcobalt sulfide into graphene frameworks for high-performance asymmetric supercapacitors. Energy Environ Sci, 2016, 9: 12991307

15 Zhou J, Wang L, Yang $\mathrm{M}$, et al. Hierarchical $\mathrm{VS}_{2}$ nanosheet assemblies: A universal host material for the reversible storage of alkali metal ions. Adv Mater, 2017, 29: 1702061
16 Li J, Liu Z, Zhang Q, et al. Anion and cation substitution in transition-metal oxides nanosheets for high-performance hybrid supercapacitors. Nano Energy, 2019, 57: 22-33

17 He G, Qiao M, Li W, et al. S,N-co-doped graphene-nickel cobalt sulfide aerogel: Improved energy storage and electrocatalytic performance. Adv Sci, 2017, 4: 1600214

$18 \mathrm{He} \mathrm{W}$, Ifraemov R, Raslin A, et al. Room-temperature electrochemical conversion of metal-organic frameworks into porous amorphous metal sulfides with tailored composition and hydrogen evolution activity. Adv Funct Mater, 2018, 28: 1707244

19 Dai Z, Geng H, Wang J, et al. Hexagonal-phase cobalt monophosphosulfide for highly efficient overall water splitting. ACS Nano, 2017, 11: 11031-11040

20 Liu W, Hu E, Jiang $\mathrm{H}$, et al. A highly active and stable hydrogen evolution catalyst based on pyrite-structured cobalt phosphosulfide. Nat Commun, 2016, 7: 10771

21 Ye R, del Angel-Vicente P, Liu Y, et al. High-performance hydrogen evolution from $\operatorname{MoS}_{2(1-x)} \mathrm{P}_{x}$ solid solution. Adv Mater, 2016, 28: $1427-1432$

22 Lin J, Wang $\mathrm{Y}$, Zheng $\mathrm{X}$, et al. $\mathrm{P}$-doped $\mathrm{NiCo}_{2} \mathrm{~S}_{4}$ nanotubes as battery-type electrodes for high-performance asymmetric supercapacitors. Dalton Trans, 2018, 47: 8771-8778

23 Kong D, Wang Y, Huang S, et al. 3D self-branched zinc-cobalt oxide@N-doped carbon hollow nanowall arrays for high-performance asymmetric supercapacitors and oxygen electrocatalysis. Energy Storage Mater, 2019, 23: 653-663

24 Guan C, Liu X, Ren W, et al. Rational design of metal-organic framework derived hollow $\mathrm{NiCo}_{2} \mathrm{O}_{4}$ arrays for flexible supercapacitor and electrocatalysis. Adv Energy Mater, 2017, 7: 1602391

25 Guan C, Xiao W, Wu H, et al. Hollow Mo-doped CoP nanoarrays for efficient overall water splitting. Nano Energy, 2018, 48: 73-80

$26 \mathrm{He} \mathrm{W}$, Wang $\mathrm{C}, \mathrm{Li} \mathrm{H}$, et al. Ultrathin and porous $\mathrm{Ni}_{3} \mathrm{~S}_{2} / \mathrm{CoNi}_{2} \mathrm{~S}_{4}$ 3D-network structure for superhigh energy density asymmetric supercapacitors. Adv Energy Mater, 2017, 7: 1700983

27 He D, Xing S, Sun B, et al. Design and construction of threedimensional flower-like $\mathrm{CuO}$ hierarchical nanostructures on copper foam for high performance supercapacitor. Electrochim Acta, 2016, 210: 639-645

28 Barai HR, Rahman MM, Joo SW. Annealing-free synthesis of Kdoped mixed-phase $\mathrm{TiO}_{2}$ nanofibers on Ti foil for electrochemical supercapacitor. Electrochim Acta, 2017, 253: 563-571

29 Chen HC, Jiang S, Xu B, et al. Sea-urchin-like nickel-cobalt phosphide/phosphate composites as advanced battery materials for hybrid supercapacitors. J Mater Chem A, 2019, 7: 6241-6249

30 Zhu J, Tang $\mathrm{S}$, Wu J, et al. Wearable high-performance supercapacitors based on silver-sputtered textiles with $\mathrm{FeCo}_{2} \mathrm{~S}_{4}-\mathrm{NiCo}_{2} \mathrm{~S}_{4}$ composite nanotube-built multitripod architectures as advanced flexible electrodes. Adv Energy Mater, 2017, 7: 1601234

31 Li S, Hua M, Yang Y, et al. Self-supported multidimensional Ni-Fe phosphide networks with holey nanosheets for high-performance all-solid-state supercapacitors. J Mater Chem A, 2019, 7: 1738617399

32 Kresse G, Furthmüller J. Efficient iterative schemes for ab initio total-energy calculations using a plane-wave basis set. Phys Rev B, 1996, 54: 11169-11186

33 Blöchl PE. Projector augmented-wave method. Phys Rev B, 1994, 50: $17953-17979$

34 Peng S, Li L, Wu HB, et al. Controlled growth of $\mathrm{NiMoO}_{4}$ nanosheet and nanorod arrays on various conductive substrates as advanced electrodes for asymmetric supercapacitors. Adv Energy 
Mater, 2015, 5: 1401172

35 Sun W, Du Y, Wu G, et al. Constructing metallic zinc-cobalt sulfide hierarchical core-shell nanosheet arrays derived from 2D metal-organic-frameworks for flexible asymmetric supercapacitors with ultrahigh specific capacitance and performance. J Mater Chem A, 2019, 7: 7138-7150

36 Shangguan H, Huang W, Engelbrekt C, et al. Well-defined cobalt sulfide nanoparticles locked in 3D hollow nitrogen-doped carbon shells for superior lithium and sodium storage. Energy Storage Mater, 2019, 18: 114-124

37 Yang Y, Li S, Huang W, et al. Effective synthetic strategy for $\mathrm{Zn}_{0.76} \mathrm{Co}_{0.24} \mathrm{~S}$ encapsulated in stabilized $\mathrm{N}$-doped carbon nanoarchitecture towards ultra-long-life hybrid supercapacitors. J Mater Chem A, 2019, 7: 14670-14680

38 Zhang $\mathrm{H}$, Wang $\mathrm{T}$, Sumboja A, et al. Integrated hierarchical carbon flake arrays with hollow P-doped $\mathrm{CoSe}_{2}$ nanoclusters as an advanced bifunctional catalyst for $\mathrm{Zn}$-air batteries. Adv Funct Mater, 2018, 28: 1804846

39 Guan C, Sumboja A, Wu $\mathrm{H}$, et al. Hollow $\mathrm{Co}_{3} \mathrm{O}_{4}$ nanosphere embedded in carbon arrays for stable and flexible solid-state zincair batteries. Adv Mater, 2017, 29: 1704117

40 Ouyang C, Wang X, Wang S. Phosphorus-doped $\mathrm{CoS}_{2}$ nanosheet arrays as ultra-efficient electrocatalysts for the hydrogen evolution reaction. Chem Commun, 2015, 51: 14160-14163

$41 \mathrm{Xu} \mathrm{X}$, Liu Y, Wang M, et al. Hierarchical hybrids with microporous carbon spheres decorated three-dimensional graphene frameworks for capacitive applications in supercapacitor and deionization. Electrochim Acta, 2016, 193: 88-95

42 Liang Z, Yang Z, Dang J, et al. Hollow bimetallic zinc cobalt phosphosulfides for efficient overall water splitting. Chem Eur J, 2018, 25: chem.201804492

43 Li S, Yang N, Liao L, et al. Doping $\beta-\mathrm{CoMoO}_{4}$ nanoplates with phosphorus for efficient hydrogen evolution reaction in alkaline media. ACS Appl Mater Interfaces, 2018, 10: 37038-37045

44 Sun J, Ren M, Yu L, et al. Highly efficient hydrogen evolution from a mesoporous hybrid of nickel phosphide nanoparticles anchored on cobalt phosphosulfide/phosphide nanosheet arrays. Small, 2019, 15: 1804272

45 Elshahawy AM, Guan C, Li X, et al. Sulfur-doped cobalt phosphide nanotube arrays for highly stable hybrid supercapacitor. Nano Energy, 2017, 39: 162-171

46 Yin X, Sun W, Lv LP, et al. Boosting lithium-ion storage performance by synergistically coupling $\mathrm{Zn}_{0.76} \mathrm{Co}_{0.24} \mathrm{~S}$ with $\mathrm{N}$-/S-doped carbon and carbon nanofiber. Chem Eng J, 2018, 346: 376-387

47 Yu Z, Bai Y, Zhang S, et al. Metal-organic framework-derived $\mathrm{Zn}_{0.975} \mathrm{Co}_{0.025} \mathrm{~S} / \mathrm{CoS}_{2}$ embedded in N,S-codoped carbon nanotube/ nanopolyhedra as an efficient electrocatalyst for overall water splitting. J Mater Chem A, 2018, 6: 10441-10446

$48 \mathrm{Lu} \mathrm{Q}$, Zou X, Ran R, et al. An "electronegative" bifunctional coating layer: Simultaneous regulation of polysulfide and Li-ion adsorption sites for long-cycling and "dendrite-free" Li-S batteries. J Mater Chem A, 2019, 7: 22463-22474

49 Wang $\mathrm{M}$, Zhang $\mathrm{C}$, Meng $\mathrm{T}$, et al. Iron oxide and phosphide encapsulated within $\mathrm{N}, \mathrm{P}$-doped microporous carbon nanofibers as advanced tri-functional electrocatalyst toward oxygen reduction/ evolution and hydrogen evolution reactions and zinc-air batteries. J Power Sources, 2019, 413: 367-375

50 Zheng X, Wu J, Cao X, et al. N-, P-, and S-doped graphene-like carbon catalysts derived from onium salts with enhanced oxygen chemisorption for $\mathrm{Zn}$-air battery cathodes. Appl Catal B-Environ,
2019, 241: 442-451

51 Zhou X, Liao X, Pan X, et al. Unveiling the role of surface $\mathrm{P}-\mathrm{O}$ group in $\mathrm{P}$-doped $\mathrm{Co}_{3} \mathrm{O}_{4}$ for electrocatalytic oxygen evolution by on-chip micro-device. Nano Energy, 2021, 83: 105748

52 Wang $\mathrm{Z}$, Liu $\mathrm{H}$, Ge R, et al. Phosphorus-doped $\mathrm{Co}_{3} \mathrm{O}_{4}$ nanowire array: A highly efficient bifunctional electrocatalyst for overall water splitting. ACS Catal, 2018, 8: 2236-2241

53 Gao J, Jiang B, Ni C, et al. Enhanced reduction of nitrate by noble metal-free electrocatalysis on $\mathrm{P}$ doped three-dimensional $\mathrm{Co}_{3} \mathrm{O}_{4}$ cathode: Mechanism exploration from both experimental and DFT studies. Chem Eng J, 2020, 382: 123034

54 Long X, Li G, Wang Z, et al. Metallic iron-nickel sulfide ultrathin nanosheets as a highly active electrocatalyst for hydrogen evolution reaction in acidic media. J Am Chem Soc, 2015, 137: 11900-11903

55 Zheng F, Yang Y, Chen Q. High lithium anodic performance of highly nitrogen-doped porous carbon prepared from a metal-organic framework. Nat Commun, 2014, 5: 5261

56 Lu Q, Yu J, Zou X, et al. Self-catalyzed growth of Co,N-codoped CNTs on carbon-encased $\operatorname{CoS}_{x}$ surface: A noble-metal-free bifunctional oxygen electrocatalyst for flexible solid $\mathrm{Zn}$-air batteries. Adv Funct Mater, 2019, 29: 1904481

57 Chen L, Yang W, Li X, et al. $\mathrm{Co}_{9} \mathrm{~S}_{8}$ embedded into N/S doped carbon composites: In situ derivation from a sulfonate-based metal-organic framework and its electrochemical properties. J Mater Chem A, 2019, 7: 10331-10337

58 Yang Q, Liu Y, Xiao L, et al. Self-templated transformation of MOFs into layered double hydroxide nanoarrays with selectively formed $\mathrm{Co}_{9} \mathrm{~S}_{8}$ for high-performance asymmetric supercapacitors. Chem Eng J, 2018, 354: 716-726

59 Liu W, Niu H, Yang J, et al. Ternary transition metal sulfides embedded in graphene nanosheets as both the anode and cathode for high-performance asymmetric supercapacitors. Chem Mater, 2018, 30: 1055-1068

60 Jia H, Wang Z, Zheng X, et al. Controlled synthesis of MOFderived quadruple-shelled $\mathrm{CoS}_{2}$ hollow dodecahedrons as enhanced electrodes for supercapacitors. Electrochim Acta, 2019, 312: 54-61

61 Jiang D, Liang H, Yang W, et al. Screen-printable films of graphene/ $\mathrm{CoS}_{2} / \mathrm{Ni}_{3} \mathrm{~S}_{4}$ composites for the fabrication of flexible and arbitrary-shaped all-solid-state hybrid supercapacitors. Carbon, 2019, 146: 557-567

62 Pan Q, Liu Y, Zhao L. $\mathrm{Co}_{9} \mathrm{~S}_{8} / \mathrm{Mo}_{2} \mathrm{~S}_{3}$ nanorods on $\mathrm{CoS}_{2}$ laminar arrays as advanced electrode with superior rate properties and long cycle life for asymmetric supercapacitors. Chem Eng J, 2018, 351: 603-612

63 Yan J, Ren CE, Maleski K, et al. Flexible MXene/graphene films for ultrafast supercapacitors with outstanding volumetric capacitance. Adv Funct Mater, 2017, 27: 1701264

64 Hu X, Liu X, Chen K, et al. Core-shell MOF-derived N-doped yolk-shell carbon nanocages homogenously filled with $\mathrm{ZnSe}$ and $\mathrm{CoSe}_{2}$ nanodots as excellent anode materials for lithium- and sodium-ion batteries. J Mater Chem A, 2019, 7: 11016-11037

65 Zong $\mathrm{Q}$, Yang $\mathrm{H}$, Wang $\mathrm{Q}$, et al. $\mathrm{NiCo}_{2} \mathrm{O}_{4} / \mathrm{NiCoP}$ nanoflake-nanowire arrays: A homogeneous hetero-structure for high performance asymmetric hybrid supercapacitors. Dalton Trans, 2018, 47: $16320-16328$

66 Lan Y, Zhao H, Zong Y, et al. Phosphorization boosts the capacitance of mixed metal nanosheet arrays for high performance supercapacitor electrodes. Nanoscale, 2018, 10: 11775-11781

67 Liu J, Wang J, Xu C, et al. Advanced energy storage devices: Basic 
principles, analytical methods, and rational materials design. Adv Sci, 2018, 5: 1700322

68 Nguyen TT, Balamurugan J, Kim NH, et al. Hierarchical 3D Zn$\mathrm{Ni}-\mathrm{P}$ nanosheet arrays as an advanced electrode for high-performance all-solid-state asymmetric supercapacitors. J Mater Chem A, 2018, 6: 8669-8681

69 Qu C, Zhang L, Meng W, et al. MOF-derived $\alpha$-NiS nanorods on graphene as an electrode for high-energy-density supercapacitors. J Mater Chem A, 2018, 6: 4003-4012

70 Zhang Q, Liu Z, Zhao B, et al. Design and understanding of dendritic mixed-metal hydroxide nanosheets@N-doped carbon nanotube array electrode for high-performance asymmetric supercapacitors. Energy Storage Mater, 2019, 16: 632-645

71 Lin J, Zhong Z, Wang H, et al. Rational constructing free-standing Se doped nickel-cobalt sulfides nanotubes as battery-type electrode for high-performance supercapattery. J Power Sources, 2018, 407: 6-13

72 Chen $\mathrm{X}$, Cheng $\mathrm{M}$, Chen $\mathrm{D}$, et al. Shape-controlled synthesis of $\mathrm{Co}_{2} \mathrm{P}$ nanostructures and their application in supercapacitors. ACS Appl Mater Interfaces, 2016, 8: 3892-3900

73 Shen L, Wang J, Xu G, et al. $\mathrm{NiCo}_{2} \mathrm{~S}_{4}$ nanosheets grown on nitrogen-doped carbon foams as an advanced electrode for supercapacitors. Adv Energy Mater, 2015, 5: 1400977

Acknowledgements This work was supported by research projects from the Department of Science and Technology of Shandong Province (2018JMRH0211, ZR2019MEM052, 2019TSLH0101 and ZR2018ZB0105), and the Fundamental Research Funds of Shandong University (2017JC042 and 2017JC010). Jun Lou was supported by a Welch Foundation grant (C-1716).

Author contributions $\mathrm{Li} \mathrm{S}$ and Si P designed the project and wrote the paper; Li S carried out most of the experiments; Hua M performed the DFT simulations; Yang Y helped with the data processing; Zheng X conducted the Raman tests; Huang W conducted the TEM and XPS measurements; Si P, Ci L and Lou J provided constructive suggestions. All authors contributed to the general discussion.

Conflict of interest The authors declare that they have no conflict of interest.

Supplementary information online version of the paper.

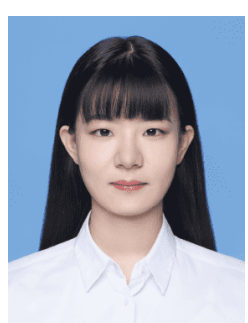

Shuo Li obtained her Bachelor degree in 2016 from the School of Materials Science and Engineering, Shandong University. She is currently a $\mathrm{PhD}$ student under the supervision of Prof. Pengchao Si at Shandong University. Her present research interests mostly concentrate on the transition metal sulfides and phosphides for energy storage applications.

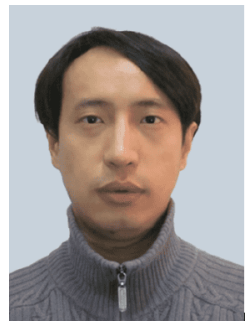

Pengchao Si received his $\mathrm{PhD}$ degree in 2007 in natural science from Roskilde University, Denmark. Then he worked as a postdoctoral research fellow in the Department of Chemistry, Curtin University. He has been a full professor at the School of Materials Science and Engineering, Shandong University since 2010. His present research interests are mainly on the synthesis of nanomaterials for energy storage, conversion and electrochemical sensors.

\section{嵌入多原子掺杂碳纳米阵列中的磷掺杂双金属硫 化物应用于柔性全固态超级电容器}

李硕 ${ }^{1}$, 华明吴 ${ }^{1}$, 杨媛 ${ }^{1}$, 郑小雯 ${ }^{1}$, 黄卫 ${ }^{2}$, 司鹏超 ${ }^{1 *}$, 慈立杰 ${ }^{1}$, 楼峻 ${ }^{3}$

摘要 柔性超级电容器具有超长使用寿命、可折叠、可穿戴等特 点, 已成为研究热点. 然而, 较低的能量密度限制了其更广泛的应 用. 本文采用简单的方法合成了一种嵌入多原子(氮, 硫和磷原子) 掺杂碳壳的磷掺杂双金属硫化物 (P-ZCS/HC) 作为高性能柔性电 极. 在退火过程中, 前驱体的三维形貌保持不变, 同时纳米片表面有 凸起的纳米球形颗粒形成, 这大大增加了电极的比表面积. 优化后 的 P-ZCS/HC电极在 $1 \mathrm{~A} \mathrm{~g}^{-1}$ 时具有 $1080 \mathrm{C} \mathrm{g}^{-1}$ 高比电容值, 且循环稳 定性出色. 这些优异的性能主要是由于该电极材料可发生丰富的 氧化还原反应, 磷化后增强的导电性, 以及磷掺杂金属硫化物和多 原子掺杂碳壳之间的协同效应. 密度泛函理论模拟表明, 磷掺杂处 理具有提高电导率、改善反应动力学和促进 $\mathrm{OH}^{-}$吸附的积极作用. 组装的全固态柔性混合超级电容器最高能量密度可达 $62.9 \mathrm{~W} \mathrm{~h} \mathrm{~kg}^{-1}$, 功率密度可达 $16 \mathrm{~kW} \mathrm{~kg}^{-1}$, 循环 10,000 次后仍能保持 初始容量的 $92.0 \%$. 这一完整和系统的研究为将来设计具有复杂成 分和优异结构的柔性电极提供了一种新的思路. 